\title{
PKR and HMGB1 expression and function in rheumatoid arthritis
}

\author{
W.J. Wang ${ }^{1}$, S.J. Yin ${ }^{1}$ and R.Q. Rong ${ }^{2}$ \\ ${ }^{1}$ Spine Surgery, The People's Hospital of Shouguang, Shouguang, \\ Shandong Province, China \\ 'Oncology, The People's Hospital of Shouguang, Shouguang, Shandong Province, \\ China \\ Corresponding author: W.J. Wang \\ E-mail: wenjunlive@126.com \\ Genet. Mol. Res. 14 (4): 17864-17870 (2015) \\ Received September 14, 2015 \\ Accepted November 25, 2015 \\ Published December 22, 2015 \\ DOI http://dx.doi.org/10.4238/2015.December.22.11
}

ABSTRACT. The pathogenesis of rheumatoid arthritis (RA) is characterized by inflammation. We aimed to examine the roles of double-stranded RNAactivated protein kinase (PKR) and high-mobility group box chromosomal protein 1 (HMGB1) in a rat model of RA. Male SD rats were divided into three groups: control, RA model, and intervention (RA model plus treatment). The model of RA was made by injecting Freund's adjuvant into the posterior right limb of the rat and the intervention group received a PKR-specific inhibitor C16 after RA modeling. The degree of limb swelling was measured following RA modeling and intervention. In addition, plasma levels of HMGB1 were determined using ELISA. The mRNA and protein levels of PKR and HMGB1 were detected in rat synovium using quantitative PCR and western blot, respectively. The degree of limb swelling in the RA model was increased compared to control, while it was decreased in the intervention model compared to the RA model. Plasma HMGB1 levels in the model group were significantly higher compared to the control group but were lower in the intervention group compared to the model group. PKR and HMGB1 protein and mRNA levels in the rat synovium were elevated in the model group and markedly reduced in the intervention group. Increased 
levels of PKR and HMGB1 in synovium or blood appear to be involved in the occurrence and development of RA in a rat model. Selective inhibition of PKR improves the symptoms of RA, perhaps by inhibiting the release of HMGB1.

Key words: Rheumatoid arthritis; Inflammatory factor; Double-stranded RNA-activated protein kinase; High-mobility group box chromosomal protein 1

\section{INTRODUCTION}

Rheumatoid arthritis (RA) is an autoimmune disease characterized by cartilage damage and joint synovitis that occurs on both sides of the body (symmetrical effect). Due to its progressive development and high rate of disability, more than half of patients show joint function damage within 1-2 years of diagnosis and some patients may also suffer from joint deformities (Behnes et al., 2015). Several studies have shown that multiple inflammatory and pro-inflammatory factors are significantly elevated in the synovial fluid and synovium of RA patients such as monocyte chemotactic protein 1, monocyte colony-stimulating factor, interleukins-1 and -6 (IL-1, IL-6), and tumor necrosis factor- $\alpha$. This suggests that inflammation is closely related to RA occurrence and development (Sato et al., 2015). High-mobility group box chromosomal protein 1 (HMGB1) is a type of non-histone nucleoprotein that is ubiquitously expressed. It participates in regulation of gene transcription and promotes chromatin stability (Hong et al., 2015). HMGB1 becomes an inflammatory factor when it leaves the cell and participates in the proliferation of multiple infectious diseases such as sepsis and endotoxin blood disease (Li et al., 2015). Double-stranded RNAactivated protein kinase $(\mathrm{PKR})$ is a serine-threonine kinase and plays an important role in antiviral infection (Ogolla et al., 2013). In this study, we examined the effect of PKR and HMGB1 in synovial tissues using a rat model of RA.

\section{MATERIAL AND METHODS}

\section{Animals and RA model development}

Thirty male SD rats were provided by the China Medical University Laboratory Animal Center. They had average weight $245 \pm 25 \mathrm{~g} \mathrm{(} \mathrm{220} \mathrm{to} 280 \mathrm{~g})$ and age 10-12 weeks. The rats were randomly divided into equal groups: control, model, and intervention. After 1 week of adaptive feeding, rats in the model and intervention groups received an injection of $0.1 \mathrm{~mL}$ Freund's complete adjuvant in the right rear footpad to induce RA (Bilasy et al., 2015). Rats in the control group received an injection of the same amount of saline in the right rear footpad. After RA modeling 7 days later, rats in the intervention group received the PKR specific inhibitor C16 $(150 \mu \mathrm{g} / \mathrm{kg})$ by intraperitoneal injection every day for 7 days (Liu et al., 2014), while the rats in the control and model groups received an equal amount of saline.

\section{Swelling degree measurement}

The degree of right foot swelling was measured in all groups before modeling, 7 days after modeling, and 7 days after intervention (Koo et al., 2015). In order to do this, the posterior 
right limb $(0.2 \mathrm{~mm})$ of each rat was immersed in $20 \mathrm{~mL}$ water. The amount of water that needed to be removed in order to bring the volume back down to $20 \mathrm{~mL}$ was measured (foot volume). The degree of swelling was determined using (foot volume 7 days after modeling - foot volume before modeling) / (foot volume before modeling) $\times 100 \%$. The degree of swelling after intervention was determined using (foot volume 7 days after intervention - foot volume 7 days after modeling) / (foot volume before modeling) $\times 100 \%$.

\section{Plasma HMGB1 level measurement}

Blood was extracted from the inferior vena cava $(3 \mathrm{~mL})$ and centrifuged at $2500 \mathrm{rpm}$ (Heraeus Multifuge, Thermo Scientific, USA) for $20 \mathrm{~min}$. The supernatant ( $1 \mathrm{~mL})$ was analyzed by ELISAaccording to the manufacturer protocol (Lengton Biological Technology Co. Ltd., Shanghai, China).

\section{Western blot}

The synovium was digested with lysis buffer (Roche Diagnostics, USA). Total protein was separated by denaturing 10\% SDS-PAGE. After incubation with anti-PKR or -HMGB1 (Sigma, USA) primary antibodies, and in turn, the secondary antibody (KPL, USA), the membrane was treated with chemiluminescence (Bio-Rad, USA) and densitometry was calculated with Quantity One (Bio-Rad, USA). Protein levels were normalized to GAPDH.

\section{Real-time PCR}

The cDNA was synthesized from $1 \mu \mathrm{g}$ RNA from the synovium samples with Trizol reagent (Invitrogen, USA) and Reverse Transcript Kit (Invitrogen, USA). The primers used were: PKR forward primer (5'-GAGGATGAAAGAAACAGCCAGCT-3'); PKR reverse primer (5'-CCCGCTATG AAATTAGATTCACGT-3'); HMGB1 forward primer (5'-GAGGATGAAAGAAACAGCCAGCT-3'); HMGB1 reverse primer (5'-CAGATCCCATTGATTTCCAC-3'); GAPDH: forward primer (5'-AACCTG CCAAGTATGATGACATCA-3'); and GAPDH reverse primer (5'-TGTTTGAAGTCACAGGAGAC AACCT-3'). The cycling conditions consisted of an initial, single cycle of $1 \mathrm{~min}$ at $90^{\circ} \mathrm{C}$, followed by 35 cycles of $10 \mathrm{~s}$ at $90^{\circ} \mathrm{C}$ and $30 \mathrm{~s}$ at $70^{\circ} \mathrm{C}$. PCR amplifications were performed in triplicate for each sample. Gene expression levels were quantified relative to the expression of GAPDH using an optimized comparative $\mathrm{Ct}\left(\Delta \Delta^{\mathrm{Ct}}\right)$ value method $2^{-\Delta \Delta \mathrm{Ct}}$.

\section{Statistical analysis}

All statistical analyses were performed using the SPSS20.0 software (Chicago, IL, USA). Differences between multiple groups were analyzed using the Bonferroni method. Numerical data are reported as means \pm standard deviation. $P<0.05$ was considered to be statistically significant.

\section{RESULTS}

\section{Confirmation of rat RA model and posterior limb swelling}

There was no mortality in any of the treatment groups. The rats in the control group were not averse to activity, responded to external stimuli well, had bright eyes, and had light red claws 
and auricles. The rats in the RA model group did not move well, had loss of reaction to stimuli, had dull eyes, and their posterior limbs showed evidence of swelling. In the intervention group, rats enjoyed activities, were responsive to external stimuli compared to those in RA model group, had bright eyes, and the posterior limb swell was obviously diminished (Figure 1). Quantitatively, the degree of swelling in the right limbs of the model group increased significantly compared to control $(P<0.05)$ while the swelling was significantly decreased in the intervention group compared to the model group $(P<0.05$; Table 1).
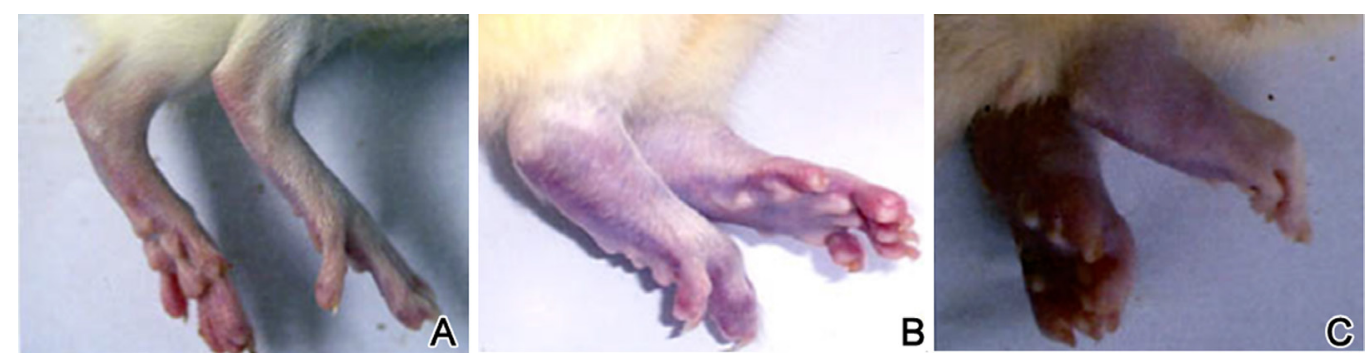

Figure 1. Posterior limb manifestation. Shown are the posterior limbs in the rats 1 week after intervention in the control group (A), model group (B), and intervention group (C).

Table 1. Comparison of degree of right foot swelling (means \pm SD, \%).

\begin{tabular}{lcccc}
\hline Group & Cases & Before model & After model & After intervention \\
\hline Control & 10 & 0 & $7.2 \pm 3.1$ & $14.9 \pm 5.8$ \\
Model & 10 & 0 & $65.2 \pm 19.6^{*}$ & $71.3 \pm 24.7^{*}$ \\
Intervention & 10 & 0 & $66.1 \pm 20.4^{*}$ & $42.5 \pm 15.4^{* \#}$ \\
\hline
\end{tabular}

${ }^{*} \mathrm{P}<0.05$, compared with control group; ${ }^{\# P}<0.05$, compared with model group.

\section{Plasma HMGB1 level comparison}

Plasma HMGB1 levels in the model group were upregulated significantly compared to the control group $(P<0.05)$, and were significantly lower in the intervention group compared to the model group $(P<0.05$; Table 2$)$.

Table 2. Comparison of HMGB1 plasma levels (means $\pm \mathrm{SD}, \mu \mathrm{g} / \mathrm{L}$ ).

\begin{tabular}{lcccc}
\hline Group & Cases & Before model & After model & After intervention \\
\hline Control & 10 & $1.29 \pm 0.17$ & $1.33 \pm 0.26$ & $1.34 \pm 0.29$ \\
Model & 10 & $1.26 \pm 0.15$ & $2.29 \pm 0.47^{\star}$ & $2.54 \pm 0.51^{\star}$ \\
Intervention & 10 & $1.31 \pm 0.19$ & $2.17 \pm 0.44^{*}$ & $1.68 \pm 0.37^{\star \#}$ \\
\hline
\end{tabular}

${ }^{*} \mathrm{P}<0.05$, compared with control group; ${ }^{\mathrm{P}}<0.05$, compared with model group.

\section{PKR and HMGB1 protein and gene expression}

After 1 week of intervention, we found that the levels of PKR and HMGB1 protein in the rat synovium were significantly elevated in the model and intervention groups compared to control $(P<0.05)$; however, the protein levels in the intervention group were lower than those of the model group $(P<0.05$; Figure 2 and Table 3$)$. The mRNA levels of PKR and HMBG1 were 
elevated in the model group compared to control $(P<0.05)$ while they were reduced (although not back to control levels) in the intervention group compared to the model group $(P<0.05$; Table 4).

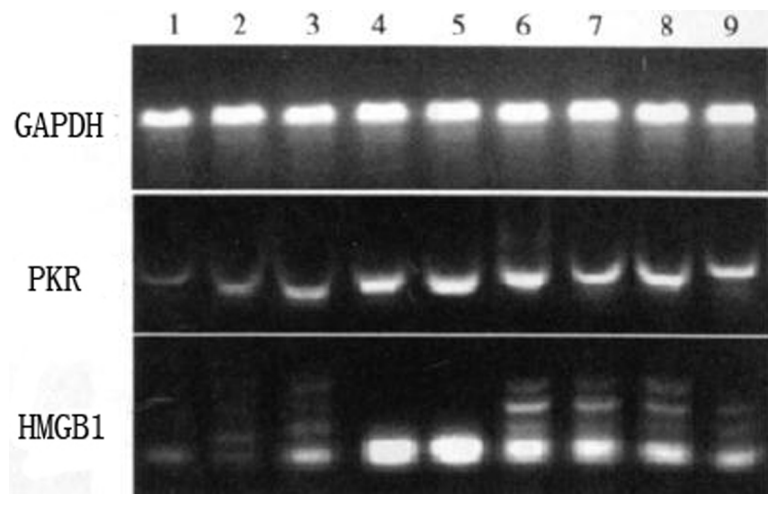

Figure 2. Western blot of PKR and HMGB1 protein expression. Lanes 1-3: control group; lanes 4-6: model group; and lanes 7-9: intervention group. GAPDH was used as an internal control.

Table 3. Levels of PKR and HMGB1 protein.

\begin{tabular}{lll}
\hline Group & PKR & HMGB1 \\
\hline Control & $0.05 \pm 0.01$ & $0.03 \pm 0.01$ \\
Model & $0.52 \pm 0.12^{\Delta}$ & $1.53 \pm 0.72^{\Delta}$ \\
Intervention & $0.26 \pm 0.09^{\Delta \Delta}$ & $0.62 \pm 0.23^{\Delta \Delta}$ \\
\hline
\end{tabular}

Densitometry was calculated with Quantity One. ${ }^{\Delta} \mathrm{P}<0.05$, compared with control group; $\Delta \mathrm{P}<0.05$, compared with model group.

Table 4. Comparison of PKR and HMGB1 gene expression (means \pm SD).

\begin{tabular}{|c|c|c|c|c|c|}
\hline \multirow[t]{2}{*}{ Group } & \multirow[t]{2}{*}{ Cases } & \multicolumn{2}{|c|}{ PKR } & \multicolumn{2}{|c|}{ HMGB1 } \\
\hline & & $\Delta^{\mathrm{Ct}}$ & Relative expression level & $\Delta^{\mathrm{Ct}}$ & Relative expression level \\
\hline Control & 5 & $0.412 \pm 0.079$ & $0.417 \pm 0.086$ & $0.023 \pm 0.009$ & $0.022 \pm 0.006$ \\
\hline Model & 5 & $0.671 \pm 0.162^{*}$ & $0.684 \pm 0.183^{*}$ & $0.331 \pm 0.023^{*}$ & $0.337 \pm 0.026^{*}$ \\
\hline Intervention & 5 & $0.672 \pm 0.159^{*}$ & $0.514 \pm 0.147^{\star \#}$ & $0.334 \pm 0.025^{*}$ & $0.179 \pm 0.014^{\star \#}$ \\
\hline
\end{tabular}

${ }^{*} \mathrm{P}<0.05$, compared with control group; ${ }^{*} \mathrm{P}<0.05$, compared with model group.

\section{DISCUSSION}

While much is known about the phenotype of RA, its mechanism of pathogenesis is not fully elucidated. A survey conducted in the 1990s focused on teenagers with RA and found that an antibody against HMGB1 was present in $45 \%$ of the patients (Rabasseda, 2014). Pullerits et al. (2006) found that HMGB1 levels were high in the joint fluid and serum of patients with RA and in the plasma of an RA model in rats. More recent studies have shown that plasma and protein levels of HMGB1 are significantly higher in RA patients and closely linked with RA pathological staging (Ke et al., 2015). HMGB1 is passively released into the extracellular space during cell death, leading to 
an increase in the mRNA levels of the cytokines IL-1 $\alpha$, IL-1 $\beta$, and IL-6. HMGB1 is also implicated in other diseases, such as pancreatitis and cancer. Xiang et al. (2014) suggested that inhibition of HMGB1 activity in patients with acute pancreatitis could improve clinical outcomes. Another study revealed that HMGB1 plays an important role in the process of malignant tumorigenesis by dysregulating cancer-related genes, promoting metastasis, and facilitating tumor growth and survival (Inoue et al., 2015). Our results found that HMGB1 mRNA levels and protein expression in plasma were both significantly elevated in a rat model of RA, which is consistent with clinical results (Bobek et al., 2014).

The human PKR gene is located on chromosome 2p21-22 and contains 17 exons. The PKR protein is ubiquitously expressed and has a strong affinity for double-stranded RNA. Its primary functions are in signal transduction and in immunity as an antiviral agent (Yoshida et al., 2012). PKR can induce apoptosis, inhibit proliferation, and act as an anti-viral agent by regulating protein translation, which could also make it an ideal marker of viral infection. Clinical studies have demonstrated that PKR is involved in multiple signaling pathways such as transcription factor 1 , transcription activation factor 3 , mitogen activated protein kinases, p53, interferon regulatory factor (IFN), and NF-kB (Couturier et al., 2011). From basic research and clinical studies (Lu et al., 2012; Kapil et al., 2014), it has been found that PKR has the following functions: inhibiting protein translation, inhibiting viral replication, inducing cell apoptosis, and inducing production of cytokines. Recent research has shown that PKR mRNA and protein levels increase significantly in RA (Yu et al., 2014). PKR may also participate in the occurrence and development of systemic lupus erythematosus, thereby increasing damage to the circulatory system. Some studies have found that HMGB1 acetylation is mediated by NF-KB in the nucleus, and it is activated by PKR to induce inflammation after release into the blood (Ito et al., 2015). In this study, PKR protein and mRNA levels were significantly higher in the RA model and intervention groups than in the control group, while they were lower in the intervention group compared to the model group. Furthermore, HMGB1 mRNA and protein levels in plasma were lower after intervention with a PKR inhibitor, suggesting that overexpression of PKR is involved in RA. Our results also demonstrate that selective inhibition of PKR could block HMGB1 release.

In conclusion, overexpression of PKR was indicative of the occurrence and development of RA in a rat model. PKR-mediated release of HMGB1 is the primary mechanism of inflammation in RA. Selective inhibition of PKR could block HMGB1 release, thereby significantly improving the symptoms of RA. In follow-up studies, we will further explore the mechanism of PKR inhibition of HMGB1 activity in RA patients to provide new insight into the mechanism of RA and potentially identify new therapeutic targets.

\section{Conflicts of interest}

The authors declare no conflict of interest.

\section{ACKNOWLEDGMENTS}

We thank the anonymous reviewers for reviewing this manuscript.

\section{REFERENCES}

Behnes M, Akin I, Borggrefe M, Traunwieser D, et al. (2015). Effect of tumor necrosis factor inhibitor treatment on proximal right coronary chronic total occlusion in a patient with rheumatoid arthritis. Circulation 131: e26-28. 
Bilasy SE, Essawy SS, Mandour MF, Ali EA, et al. (2015). Myelosuppressive and hepatotoxic potential of leflunomide and methotrexate combination in a rat model of rheumatoid arthritis. Pharmacol. Rep. 67: 102-114.

Bobek D, Grcevic D, Kovacic N, Lukić IK, et al. (2014). The presence of high mobility group box-1 and soluble receptor for advanced glycation end-products in juvenile idiopathic arthritis and juvenile systemic lupus erythematosus. Pediatr. Rheumatol. Online J. 12: 50.

Couturier J, Paccalin M, Morel M, Terro F, et al. (2011). Prevention of the beta-amyloid peptide-induced inflammatory process by inhibition of double-stranded RNA-dependent protein kinase in primary murine mixed co-cultures. J. Neuroinflammation 8: 72.

Hong SH, Cho JG, Yoon KJ, Lim DS, et al. (2015). The antibody atliximab attenuates collagen-induced arthritis by neutralizing AIMP1, an inflammatory cytokine that enhances osteoclastogenesis. Biomaterials 44: 45-54.

Inoue S, Kiriyama K, Hatanaka $\mathrm{Y}$ and Kanoh H (2015). Adsorption properties of an activated carbon for 18 cytokines and HMGB1 from inflammatory model plasma. Colloids Surf. B 126: 58-62.

Ito H, Fujita K, Tagawa K, Chen X, et al. (2015). HMGB1 facilitates repair of mitochondrial DNA damage and extends the lifespan of mutant ataxin-1 knock-in mice. EMBO Mol. Med. 7: 78-101.

Kapil P, StohIman SA, Hinton DR and Bergmann CC (2014). PKR mediated regulation of inflammation and IL-10 during viral encephalomyelitis. J. Neuroimmunol. 270: 1-12.

Ke S, Zhou F, Yang H, Wei Y, et al. (2015). Downregulation of high mobility group box 1 modulates telomere homeostasis and increases the radiosensitivity of human breast cancer cells. Int. J. Oncol. 46: 1051-1058.

Koo BS, Hong S, Kim YJ, Kim YG, et al. (2015). Mortality in patients with rheumatoid arthritis-associated interstitial lung disease treated with an anti-tumor necrosis factor agent. Korean J. Intern. Med. 30: 104-109.

Li L, Ling Y, Huang M, Yin T, et al. (2015). Heparin inhibits the inflammatory response induced by LPS and HMGB1 by blocking the binding of HMGB1 to the surface of macrophages. Cytokine 72: 36-42.

Liu Q, Zhao J, Tan R, Zhou H, et al. (2015). Parthenolide inhibits pro-inflammatory cytokine production and exhibits protective effects on progression of collagen-induced arthritis in a rat model. Scand. J. Rheumatol. 44: 182-191.

Lu B, Nakamura T, Inouye K, Li J, et al. (2012). Novel role of PKR in inflammasome activation and HMGB1 release. Nature 488: 670-674.

Ogolla PS, Portillo JA, White CL, Patel K, et al. (2013). The protein kinase double-stranded RNA-dependent (PKR) enhances protection against disease cause by a non-viral pathogen. PLoS Pathog. 9: e1003557.

Pullerits R, Brisslert M, Jonsson IM, Tarkowski A, et al. (2006). Soluble receptor for advanced glycation end products triggers a proinflammatory cytokine cascade via beta2 integrin Mac-1. Arthritis Rheum. 54: 3898-3907.

Rabasseda X (2014). A report from the 2014 American College of Rheumatology/Association of Rheumatology Health Professionals Annual Meeting (November 14-19, Boston, Massachusetts, USA). Drugs Today (Barc) 50: 829-841.

Sato E, Tanaka E, Ochiai M, Shimizu Y, et al. (2015). Chronological changes in baseline disease activity of patients with rheumatoid arthritis who received biologic DMARDs between 2003 and 2012. Mod. Rheumatol. 25: 350-357.

Xiang K, Cheng L, Luo Z, Ren J, et al. (2014). Glycyrrhizin suppresses the expressions of HMGB1 and relieves the severity of traumatic pancreatitis in rats. PLoS One 9: e115982.

Yoshida K, Okamura H, Ochiai K, Hoshino Y, et al. (2012). PKR plays a positive role in osteoblast differentiation by regulating GSK-3beta activity through a beta-catenin-independent pathway. Mol. Cell. Endocrinol. 361: 99-105.

Yu JI, Park YR, Lee SS and Chae SC (2014). Polymorphisms of interleukin-31 are associated with anti-CCP levels in females with rheumatoid arthritis. J. Genet. 93: 813-817. 